\title{
Comparison of Release Retardant Effect of Some Novel Lipids by Formulating Sustained Release Tablet of BCS Class 1 Drug
}

\author{
Rajni Devi, Ram Babu Sharma, Abhishek Sharma, Shweta Agarwal* \\ Department of Pharmaceutics, L.R. Institute of Pharmacy, Solan, Himachal Pradesh, INDIA.
}

\begin{abstract}
Aim: The study was carried out with the objective of comparing the release retardant effect of some novel lipids by preparing sustained release tablets of highly watersoluble drug, theophylline. Methods: The tablets were a mixture of theophylline and each of the three novel lipids taken in different ratios (Compritol ATO 888, Precirol ATO 5, Dynasan 114) prepared by Direct compression method. Drug and novel lipids interaction was determined by FTIR spectroscopy and DSC while drug release from the sustained release tablets was studied using USP-II dissolution apparatus. The release was analysed to determine the lipid showing the best retardant effect. It was also subjected to different kinetic models to evaluate the release kinetics and mechanism of release. Statistical analysis was done on in-vitro release data by ordinary one-way ANOVA to check for significant difference in release for different formulation. The hardness and other evaluation parameters of the tablets were within acceptable range. Results: FTIR and DSC showed no interaction between the drug and the lipids of the formulations (DC1 to DC9) and DC1 formulation showed the best sustained release in $12 \mathrm{hr}$. The result of release retardant effect given by the lipids is in the order dynasan < precirol < compritol. Conclusion: The study showed that Compritol ATO 888 (glyceryl behenate) was highly hydrophobic lipid and therefore showed best sustained release of water-soluble drug theophylline as compared to Precirol ATO 5 (glyceryl palmitostearate) and Dynasan 114 (glyceryl tri myristate) lipids.
\end{abstract}

Key words: Theophylline, Direct Compression, Sustained Release, Compritol ATO 888 , Precirol ATO 5, Dynasan 114.

\section{INTRODUCTION}

Any drug or dosage form modification prolonging the therapeutic activity of drug can be defined as a sustained release dosage form. ${ }^{1}$ The principal objectives of sustained drug delivery are safety, enhancement of efficacy of drug and better patient compliance. Sustained drug delivery systems are becoming popular in the treatment of acute and chronic diseases because of maintenance of concentration of drug in plasma above the minimum effective concentration and below the maximum safe level for an extended period of time. Thus, sustained drug delivery systems achieve optimum drug therapy with reduced dosing frequency and reduced side effects. ${ }^{2}$
Theophylline (BCS class-1) is a methyl xanthine drug, clinically used as bronchodilator and in asthma usually as oral formulations. ${ }^{3}$ Its action as non-selective inhibitor of cyclic nucleotide phosphodiesterases causes relaxation of the airway smooth muscle cells, making it useful in the treatment of asthma and COPD (chronic obstructive pulmonary disease) ${ }^{4-6}$ Its biological half- life is $3-4 \mathrm{hr}$ and it has a narrow therapeutic concentration range of 10 to $20 \mu \mathrm{g} / \mathrm{mL}$. Toxicity typically appears at concentration above $20 \mu \mathrm{g} / \mathrm{mL}$ but fluctuations in its serum concentrations may cause variability in clinical response. Theophylline was selected as the model
Submission Date: 29-09-2019; Revision Date: 26-12-2019; Accepted Date: 12-03-2020

DOI: 10.5530/ijper.54.2s.80 Correspondence: Mrs. Shweta Agarwal Department of

Pharmaceutics, L.R. Institute of Pharmacy, Jabli-Kyar, Ochghat, Solan-173223 Himachal Pradesh, INDIA. Phone: +919882032426 E-mail: shweta_ag26@ rediffmail.com

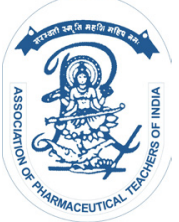

www.ijper.org 
drug to study the release retardant effect of the three novel lipids as it a highly soluble BCS class-1 drug. ${ }^{7,8}$

Lipids are biological molecules showing limited aqueous solubility and also hampered solubility in non-polar organic solvents. They have dominant intermolecular hydrophobic and van der Waals interactions. However, some lipids are amphipathic in nature, interacting via hydrogen bonding and electrostatic interactions with aqueous based solvents. ${ }^{9,10}$ Novel lipids are the new chemical entities, designed using increasingly available receptor structural information. ${ }^{11}$ Novel lipids are increasingly being used for modification of drug release from dosage forms because of their inertness resistance to changes in drug release on change in $\mathrm{pH} .{ }^{12}$

Till date several studies have been carried out by using novel lipids in sustained release dosage form. Sustained release tablet of drug Etoricoxib, ${ }^{13}$ Aceclofenac, ${ }^{14}$ Glipizide $^{15}$ have been formulated using lipids like glyceryl monostearate and glyceryl behenate for Etoricoxib, Compritol for Aceclofenac and Compritol and stearic acid for Glipizide, for studying the release retardant effect of lipids used.

Kalakuntta et al. carried out a study using theophylline as the drug and compritol ATO 888, Precirol ATO 5 and Geleol as lipids revealing Compritol to be the lipid sustaining the release to the greatest extent. Janin et al. also formulated theophylline sustained release tablet using Compritol ATO 888 as release retardant but different pore forming agents like lactose or dibasic calcium phosphate anhydrous. ${ }^{16}$

Theophylline sustained release tablet were also formulated using dika fat and Minitab using Compritol ATO 888, showing these lipids to successfully retard the release of drug. ${ }^{17}$

But no study has been conducted, so far, comparing the release retardant effect of Compritol ATO 888, Precirol ATO 5and Dynasan 114 on theophylline, it being a highly Soluble BCS class I drug.

So, in this research novel lipids Compritol ATO 888 (glyceryl behenate), Dynasan 114 (glyceryl trimyristate) and precirol ATO 5 (glyceryl palmitostearate) were used for formulating sustain release tablets of theophylline by direct compression method. Each novel lipid was used at three levels of drug: lipid ratio (100:100, 100:125, 100:150) for preparing tablets. The tablets prepared were subjected to in-vitro drug release to determine the release retardant effect of lipids in sustaining the release of drug. The lipid showing the least in-vitro release at the end of testing period was considered to possess the best potential for sustaining the release of the drug. ${ }^{18,19}$ Composition of various batches has been shown in Table 1.

\section{MATERIALS AND METHODS}

\section{Materials}

Theophylline was obtained from Yarrow Chem product, Mumbai, India. Compritol ATO 888 and Precirol ATO 5 were obtained ex-gratia from Gattefosse Corp, France. Dynasan 114 was a gift sample from IOI Oleo $\mathrm{GmbH}$ Corp, Germany.

\section{Formulation of sustain release tablets of Theophylline}

\section{Granulation by using Iso-propyl alcohol}

Drug and lipids were blended for 15 min then granulated by addition of Iso propyl alcohol in sufficient quantity. The moist mass was made to pass through $20 \#$ sieve and air dried for $45 \mathrm{~min}$. Dried granules were passed through $25 \#$ sieve and thereafter compressed into tablets using single rotary tablet compression machine (Pilot press) using $6 \mathrm{~mm}$ and $8 \mathrm{~mm}$ size of dies and punch set $(100 \mathrm{mg}$ and $125 \mathrm{mg}$ tablets were compressed in the size of $6 \mathrm{~mm}$ dies and punch and $150 \mathrm{mg}$ was compressed in $8 \mathrm{~mm}$ dies and punch set).

Tablets were formulated by using each lipid in 3 different ratios with respect to the drug. The drug: lipid ratios taken for each lipid were 1:1, 1:1.25, 1:1.5 (Table 1).

\begin{tabular}{|c|c|c|c|c|}
\hline \multicolumn{5}{|c|}{$\begin{array}{c}\text { Table 1: Formulation composition of sustained } \\
\text { release tablets (Theophylline with Novel lipids). }\end{array}$} \\
\hline $\begin{array}{c}\text { Sr. } \\
\text { No. }\end{array}$ & $\begin{array}{c}\text { Formulation } \\
\text { Code }\end{array}$ & $\begin{array}{c}\text { Drug: novel } \\
\text { lipid ratio }\end{array}$ & $\begin{array}{c}\text { Weight of } \\
\text { drug + lipid } \\
\text { (g) }\end{array}$ & $\begin{array}{c}\text { Total } \\
\text { weight } \\
\text { (g) }\end{array}$ \\
\hline 1 & DC1 & $\begin{array}{c}\text { TP: Comp } \\
(1: 1)\end{array}$ & $100+100$ & 200 \\
\hline 2 & DC2 & $\begin{array}{c}\text { TP: Comp } \\
(1: 1.25)\end{array}$ & $100+125$ & 225 \\
\hline 3 & DC3 & $\begin{array}{c}\text { TP: Comp } \\
(1: 1.5)\end{array}$ & $100+150$ & 250 \\
\hline 4 & DC4 & TP: Pre (1:1) & $100+100$ & 200 \\
\hline 5 & DC5 & $\begin{array}{c}\text { TP: Pre } \\
(1: 1.25)\end{array}$ & $100+125$ & 225 \\
\hline 6 & DC6 & $\begin{array}{c}\text { TP: Pre } \\
(1: 1.5)\end{array}$ & $100+150$ & 250 \\
\hline 7 & DC7 & TP: Dyn (1:1) & $100+100$ & 200 \\
\hline 8 & DC8 & $\begin{array}{c}\text { TP: Dyn } \\
(1: 1.25)\end{array}$ & $100+125$ & 225 \\
\hline 9 & DC9 & $\begin{array}{c}\text { TP: Dyn } \\
(1: 1.5)\end{array}$ & $100+150$ & 250 \\
\hline
\end{tabular}

TP: Theophylline, Comp: Compritol ATO 888, Pre: Precirol ATO 5, Dyn: Dynasan 114. 


\section{Drug-Excipient Compatibility studies by Fourier Transform Infra- Red (FTIR) spectroscopy and DSC}

Drug and lipids interactions were studied by Fourier Transform Infrared Spectroscopy (FTIR) (PerkinElmer Spectrum Version 10.5.1). The spectra were obtained for the drug and compressed mixture of drug with each of the three novel lipids over a scanning range of 4000-650. The recorded spectrum of drug was compared with the spectra of physical mixture to detect drug-lipid interaction by major shifts in peaks. ${ }^{20}$

\section{Differential scanning calorimetry (DSC)}

DSC thermograms of the drug and compressed tablet of binary mixture of drug and lipids were recorded on a TA instrument USA Model-Q10. DSC was done to determine any possible interaction between the drug and lipids. Temperature range of $30-350^{\circ} \mathrm{C}$ at a heating rate $5^{\circ} \mathrm{C} / \mathrm{min}$ in an atmosphere of nitrogen was used for obtaining DSC graphs. Minor shifts in the endothermic peaks of the drug and lipids mixtures are considered acceptable due to the presence of other components as impurity.

\section{Angle of repose}

Funnel method was used for the determination of angle of repose. Accurately weighed granules were taken in a funnel and were allowed to flow freely on to the surface so as to form a conical heap. The funnel's height was so adjusted so that the apex of heap touched the tip of funnel stand. The diameter and the height of the conical heap of powder were recorded and angle of repose was calculated by the following equation.

$$
\theta=\tan ^{-1} \mathrm{~h} / \mathrm{r}
$$

equation 1.

Where, $\theta=$ angle of repose

$\mathrm{h}=$ height of heap,

$r=$ radius of the heap base

\section{Bulk density}

Both bulk density (BD) and tapped density (TD) were determined by taking a quantity of $10 \mathrm{~g}$. of powder blend from each formula, previously shaken to break any agglomerates formed. This was introduced in to a $100 \mathrm{ml}$ measuring cylinder. The initial volume was recorded and the cylinder was set in bulk density apparatus (PT Ambala Cantt, India) and tapped until no further change in volume seen. BD and TD were calculated by the following equations.

$$
\begin{aligned}
\mathrm{BD}= & \text { weight of powder blend / untapped } \\
& \text { volume of packing }
\end{aligned}
$$

TD = weight of powder blend / Tapped volume of packing equation 3 .

\section{Compressibility Index}

Carr's compressibility index was used to measure the compressibility index of the powdered blends. Carr's Index was calculated by using the given equation.

Carr's Index $(\%)=$ TD-BD $/ \mathrm{TD}^{*} 100 \quad$ equation 4.

Where, $\mathrm{TD}=$ Tapped bulk density

$$
\mathrm{BD}=\text { Loose bulk density }
$$

\section{Hausner's Ratio}

The ratio of bulk volume to tapped volume or tapped density to bulk density was used for the calculation of Hausner's ratio. It was calculated by the following formula.

$$
\text { Hausner's Ratio }=\mathrm{V}_{0} / \mathrm{V} \quad \text { equation } 5 .
$$

Where, $\mathrm{V}_{0}=$ Bulk volume

$$
\mathrm{V}=\text { Tapped Volume }
$$

\section{Post compression evaluation}

\section{Thickness}

Vernier calliper was used for the evaluation of thickness of tablets. Five tablets from each batch were taken and average values were calculated. The tablets were placed between the two arms of vernier callipers for determining the thickness.

\section{Hardness}

The hardness of 5 tablets was determined from each formulation by using Monsanto hardness tester. The value was noted in $\mathrm{kg}$ and results were expressed as mean $\pm \mathrm{SD}(n=5)$.

\section{Friability}

Roche friabillator (Swastika, India) was used for checking the friability of tablets. Tablets of a known weight $\left(\mathrm{W}_{0}\right)$ were placed in the drum of friabillator at a speed of $25 \mathrm{rpm}$ for $4 \mathrm{~min}$ (100 revolutions), dropping the tablets from a distance of 6 inches in each revolution. The tablets were weighed (Wt) again. Percentage friability was calculated from the loss in weight as given in equation. The weight loss should not exceed than $1 \%$.

$$
\% \text { Friability }=\mathrm{W} 0-\mathrm{Wt} / \mathrm{W} 0 * 100
$$

\section{In-vitro drug release studies of Theophylline matrix tablets}

The in-vitro dissolution study of Theophylline tablets was conducted by using USP dissolution apparatus (Frontline $\triangle$ ELTA TP02). Phosphate buffer pH6.8 in 
the quantity of $900 \mathrm{ml}$ was used as dissolution medium for $12 \mathrm{hr}$ study. Temperature was maintained at $37 \pm 0.5^{\circ} \mathrm{C}$. Agitation was provided by rotating the paddle at $75 \mathrm{rpm}$. At predetermined time intervals $5 \mathrm{ml}$ sample was withdrawn, filtered, suitably diluted and its absorbance was checked at $272 \mathrm{~nm}$ by UV Spectrophotometer (Max Electronic, India). Six tablets were $(n=0)$ subjected to dissolution studies. The graphs of time vs. $\%$ cumulative release were plotted for each batch of formulated tablets.

\section{Kinetics of the drug release}

The in-vitro drug release data of the selected formulation was subjected to kinetic modelling by fitting the data into different kinetic models like zero order, first order, Higuchi and Korsmeyer-peppas model to establish the drug release mechanism and kinetics. The following equations were used for kinetic modelling. ${ }^{21,22}$

$\mathrm{Q}_{\mathrm{t}}=\mathrm{Q}_{0}+\mathrm{K}_{0} \mathrm{t}$ (Zero order Kinetics)

equation 6.

[Where $\mathrm{Q}_{\mathrm{t}}=$ drug dissolved in time $\mathrm{t}$,

$\mathrm{Q}_{0}=$ initial amount of drug in the solution and $\mathrm{K}_{0}=$ zero order release constant.$^{23}$

$\mathrm{Q}_{\mathrm{t}}=\mathrm{Q}_{0}+\mathrm{K}_{1} \mathrm{t} / 2.303$ (First order Kinetics) equation 7 .

Where $Q_{t}=$ amount of the drug released in time $t$,

$\mathrm{Q}_{0}=$ initial amount of drug in the solution and $\mathrm{K}_{1}=$ first order release constant]. ${ }^{24}$

$\mathrm{Q}_{\mathrm{t}}=\mathrm{K}_{\mathrm{H}} \mathrm{t}^{1 / 2}$ (Higuchi model) equation 8 .

[Where $Q_{t}=$ amount of drug released in time $t$,

$\mathrm{K}_{\mathrm{H}}=$ Higuchi dissolution constant $] .{ }^{25}$

$\mathrm{Q}_{\mathrm{t}}=\mathrm{a}+\mathrm{n} \log \mathrm{t}$ (Korsmeyer-peppas model) equation 9.

[Where $Q_{t}=$ amount of drug released in time $t$,

$\mathrm{a}^{\prime}=$ constant incorporating structural and geometric characteristic of the drug dosage form,

$\mathrm{n}=$ release exponent]. ${ }^{26}$

\section{Statistical analysis used}

Statistical analysis was done on in-vitro drug release data by using the trial version of the software Graphpad Prism version 8.3.0. The release of drug from the different formulation batches was subjected to ordinary one way ANOVA to check for significant difference in the release at $p<0.05$.

The calculated $p$-value was compared with the tabulated $p$-value to check for significant difference in release on changing the lipid type and lipid ratio. $P$-value less than 0.05 was considered significant.

\section{RESULTS \\ Compatibility study}

Fourier Transform Infrared Spectroscopy (FTIR) was used to study the possible chemical interactions between the drug and the lipids during the preparation of tablets. IR spectroscopic study gave no evidence of interaction between the drug and lipids as can be seen from Figures 1a-1d.

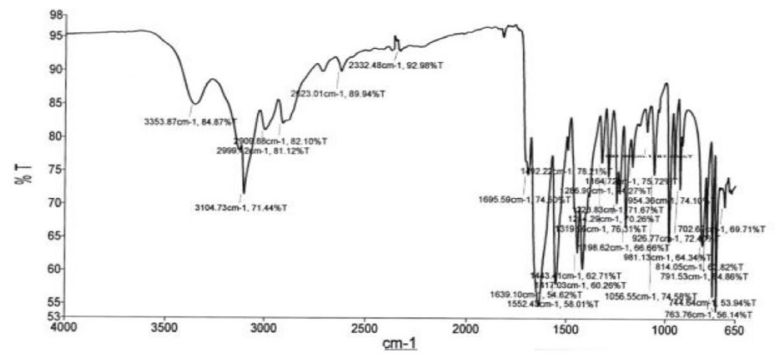

(a)

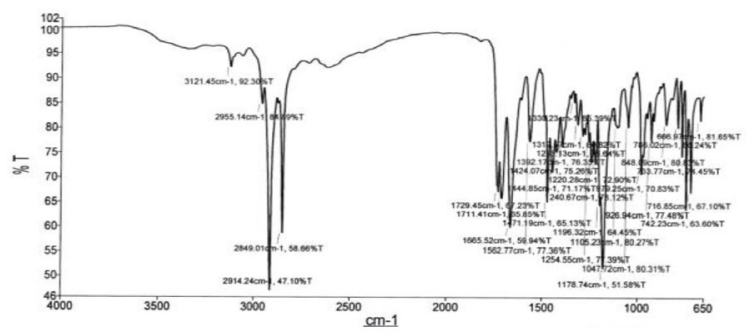

(b)

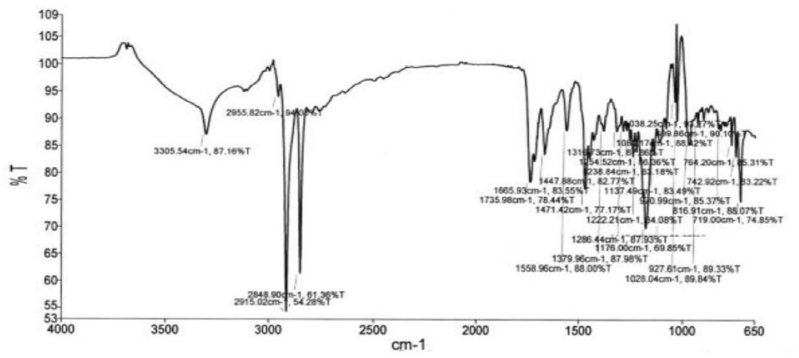

(c)

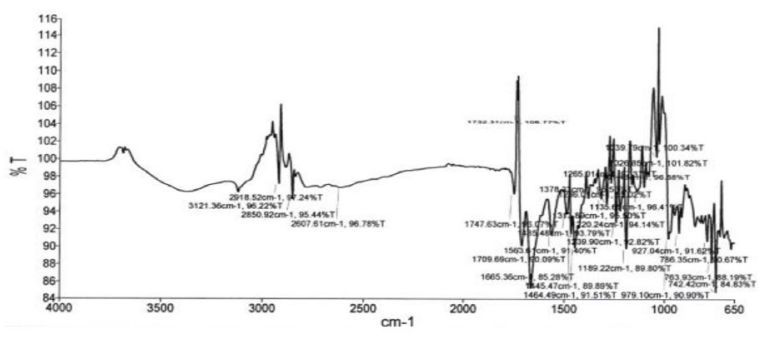

(d)

Figure 1: FTIR spectroscopy of (a) Theophylline (b) Theophylline+Compritol ATO 888 (c) Theophylline+Precirol ATO 5 (d) Theophylline+Dynasan 114. 
Figure 2 shows thermogram of theophylline and compressed binary mixture of theophylline with lipids compritol ATO 888, precirol ATO 5 and dynasan 114. Thermogram of theophylline shows a sharp peak at $272.6^{\circ} \mathrm{C}$ representing the point at which it melts as has also been reported in literature. ${ }^{27}$ Thermograms of binary compressed mixtures of drug with lipid, compritol ATO 888 [Figure 2(b)], precirol ATO 5 [Figure 2(c)], dynasan 114 [Figure 2(d)] showed endothermic peaks at $262.6^{\circ} \mathrm{C}, 263.8^{\circ} \mathrm{C}$ and $270.4^{\circ} \mathrm{C}$ respectively, representing the melting point of the drug. Endothermic peaks at $71.1^{\circ} \mathrm{C}, 55.2^{\circ} \mathrm{C}$ and $54.5^{\circ} \mathrm{C}$ in the binary mixture graphs represent the melting point of lipids compritol ATO 888, precirol ATO 5 and dynasan

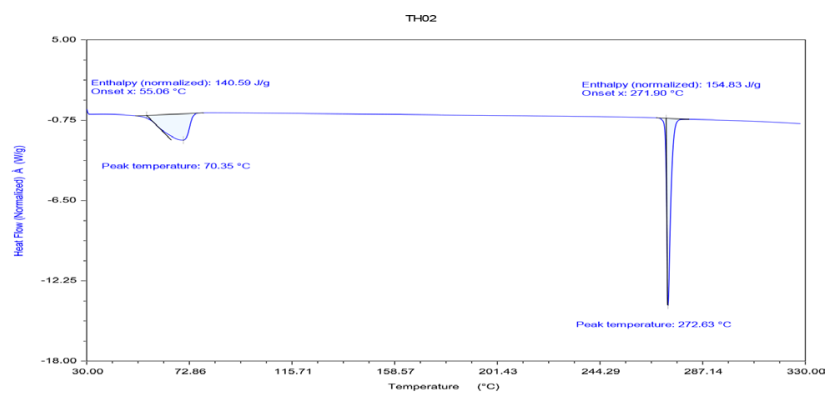

(a)

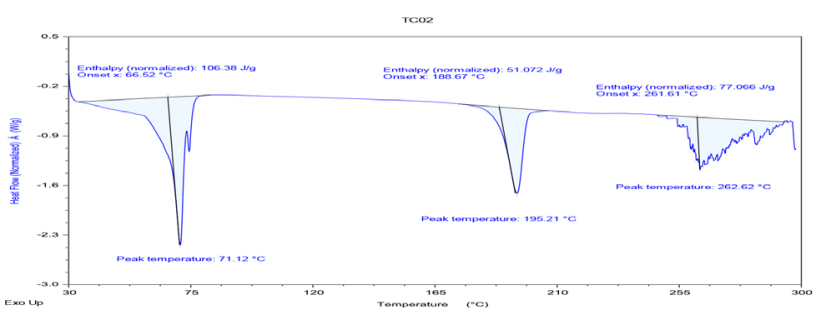

(b)

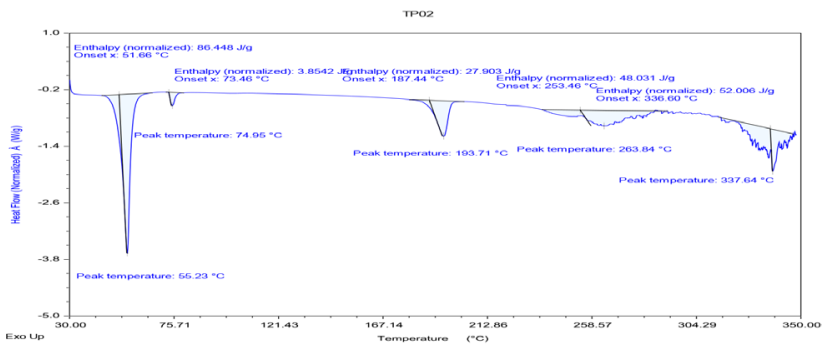

(c)

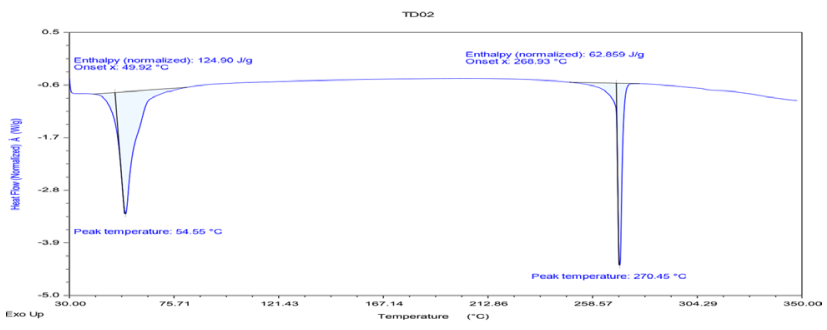

(d)

Figure 2: Differential Scanning Calorimetry Graph of (a) Theophylline (b)Theophylline+Compritol ATO 888 (c) Theophylline+Precirol ATO 5 (d) Theophylline+Dynasan 114
114 respectively. ${ }^{28-32}$ Presence of separate peaks of the drug and lipids in the binary mixture graphs clearly indicates no incompatibility between the drug and the lipids.

\section{Pre compression evaluation}

The different micrometrics properties of the granules from each formulation batch have been summarized in Table 2. The granules of various formulation batches containing drug and novel lipid were evaluated for the angle of repose, Bulk Density (BD), Tapped Density (TD), Carr's index, Hausner ratio. The results of pre compression evaluation showed granules of the batches to possess appropriate qualities for compression into tablets. Angle of repose ranged from 25-28 demonstrating adequate flow property in the granules. Carr's index and Hausner's ratio, $12-15 \%$ and $0.85-0.87$ respectively, established adequate flow of granules. Compressibility index for all formulations were found to be in the range of $12-15 \%$. The values for $\mathrm{BD}$ and TD were found to be in the range of $0.46-0.83 \mathrm{~g} / \mathrm{cm}^{3}$ and $0.53-0.96 \mathrm{~g} / \mathrm{cm}^{3}$ indicating good packing capacity.

\section{Post compression evaluation}

Tablets of each formulation batch were evaluated for parameters like Thickness, diameter, Hardness and Friability (Table 3). The results of thickness were consistent throughout as can be seen from Table 3. The hardness of tablet was checked by Monsanto hardness tester. The hardness was in range of $5.2 \pm 0.1-6.36 \pm 0.115 \mathrm{~kg} / \mathrm{cm}^{2}$. Friability was found to be $0.67 \pm 0.0-0.87 \pm 0.01 \%$. All the tablets passed the weight variation test.

Figure 3 Shows the in-vitro drug release profile for all the formulated batches and Table 4 shows the percentage drug release for the formulated batches at $1 \mathrm{hr}, 6 \mathrm{hr}$ and $12 \mathrm{hr}$. The results of drug release data can be discussed under two heads, effect of change in type of lipid and effect of change of drug: lipid ratio.

\section{Effect of changing the lipid type}

The release data clearly shows that at lower levels of lipids (at 1:1 level) there is a discernible change in release rate on changing the lipid type at all the time points considered (at $1 \mathrm{hr}, 6 \mathrm{hr}$ and $12 \mathrm{hr}$ ) but as the lipid level in increased to 1.25 and 1.5 the difference becomes smaller and almost insignificant. When the $12^{\text {th }} \mathrm{hr}$ data for different lipids was statistically analyzed by ordinary one way-ANOVA at $(p<0.05)$, the results showed significant difference in release for Dynasan 1:1, precirol1:1 and Compritol1:1 (calculated $p<0.0001$ ) but insignificant difference for different lipids when used at $1: 1.25$ and $1: 1.5$ ratios as the calculated $p=0.3206$ for $1: 1.25$ ratio and $p=0.8757$ for $1: 1.5$ ratio (Table 5). From these results Compritol shows the best potential for retarding 
Table 2: Evaluation of micrometrics properties of the granules.

\begin{tabular}{|c|c|c|c|c|c|}
\hline Formulation Code & Angle of repose & BD $^{*}\left(\mathbf{g} / \mathbf{c m}^{\mathbf{3}}\right)$ & TD $^{*}\left(\mathbf{g} / \mathbf{c m}^{3}\right)$ & Carr's index* (\%) & Hausner's Ratio* $(\%)$ \\
\hline DC1 & $26.12 \pm 0.05$ & $0.62 \pm 0.04$ & $0.71 \pm 0.01$ & $12.67 \pm 0.02$ & $0.87 \pm 0.01$ \\
\hline DC2 & $25.59 \pm 0.01$ & $0.58 \pm 0.05$ & $0.66 \pm 0.01$ & $12.12 \pm 0.02$ & $0.88 \pm 0.05$ \\
\hline DC3 & $26.06 \pm 0.05$ & $0.69 \pm 0.01$ & $0.79 \pm 0.05$ & $12.65 \pm 0.05$ & $0.87 \pm 0.01$ \\
\hline DC4 & $27.32 \pm 0.02$ & $0.57 \pm 0.03$ & $0.66 \pm 0.03$ & $13.63 \pm 0.03$ & $0.86 \pm 0.05$ \\
\hline DC5 & $26.13 \pm 0.01$ & $0.46 \pm 0.01$ & $0.53 \pm 0.05$ & $13.20 \pm 0.05$ & $0.86 \pm 0.02$ \\
\hline DC6 & $27.08 \pm 0.05$ & $0.55 \pm 0.05$ & $0.64 \pm 0.02$ & $14.06 \pm 0.04$ & $0.85 \pm 0.04$ \\
\hline DC7 & $25.78 \pm 0.01$ & $0.64 \pm 0.02$ & $0.73 \pm 0.04$ & $12.32 \pm 0.03$ & $0.87 \pm 0.03$ \\
\hline DC8 & $27.17 \pm 0.02$ & $0.83 \pm 0.05$ & $0.96 \pm 0.02$ & $13.54 \pm 0.05$ & $0.86 \pm 0.05$ \\
\hline DC9 & $26.25 \pm 0.04$ & $0.72 \pm 0.01$ & $0.84 \pm 0.05$ & $14.28 \pm 0.01$ & $0.85 \pm 0.02$ \\
\hline
\end{tabular}

*Results are expressed as mean \pm SD, where $n=3$. SD: Standard deviation

\begin{tabular}{|c|c|c|c|c|}
\hline Formulation code & Thickness* (mm) & Diameter* (mm) & Hardness* (kg/cm2) & Friability (\%) \\
\hline DC1 & $3.43 \pm 0.028$ & $8.13 \pm 0.036$ & $5.76 \pm 0.057$ & $0.82 \pm 0.01$ \\
\hline DC2 & $3.66 \pm 0.057$ & $8.23 \pm 0.055$ & $6.23 \pm 0.115$ & $0.85 \pm 0.03$ \\
\hline DC3 & $3.18 \pm 0.037$ & $10.06 \pm 0.047$ & $5.26 \pm 0.057$ & $0.73 \pm 0.05$ \\
\hline DC4 & $3.56 \pm 0.046$ & $8.13 \pm 0.047$ & $6.03 \pm 0.057$ & $0.77 \pm 0.02$ \\
\hline DC5 & $3.73 \pm 0.052$ & $8.16 \pm 0.039$ & $6.36 \pm 0.115$ & $0.87 \pm 0.03$ \\
\hline DC6 & $3.16 \pm 0.057$ & $10.1 \pm 0.029$ & $5.26 \pm 0.057$ & $0.69 \pm 0.01$ \\
\hline DC7 & $3.53 \pm 0.028$ & $8.16 \pm 0.057$ & $6.16 \pm 0.057$ & $0.73 \pm 0.04$ \\
\hline DC8 & $3.76 \pm 0.039$ & $8.26 \pm 0.046$ & $6.33 \pm 0.057$ & $0.67 \pm 0.01$ \\
\hline DC9 & $3.13 \pm 0.046$ & $10.13 \pm 0.053$ & $5.2 \pm 0.18$ & $0.71 \pm 0.03$ \\
\hline
\end{tabular}

"Results are expressed as mean \pm SD, where $n=3$. SD: Standard deviation

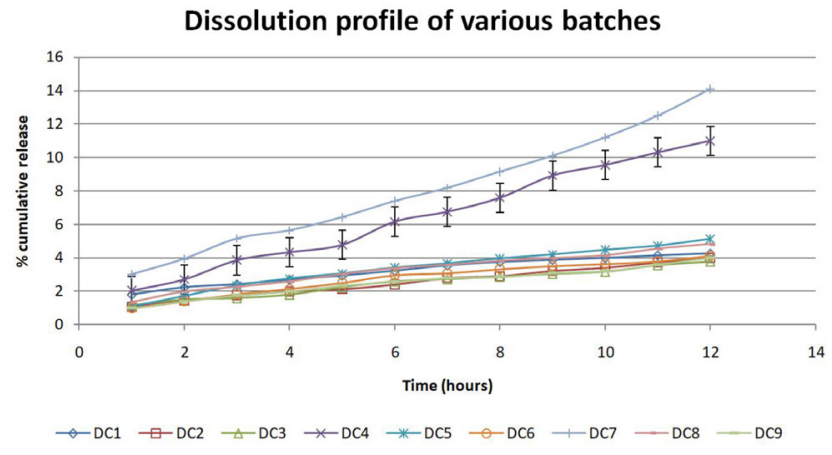

Figure 3: In-vitro drug release profile of various formulation batches.

the release of the drug (as it gives the least release at $1 \mathrm{hr}, 6 \mathrm{hr}$ and $12 \mathrm{hr}) .{ }^{33,34}$ Similar results have been reported by Kalakuntta et al. in formulating theophylline sustained release tablet using Compritol ATO 888, Precirol ATO 5 and Geleol as lipid and also by Abd-Elbary et al. in formulating Etodolac sustained release tablets using different lipids. ${ }^{35}$

\section{Effect of change in drug: lipid ratio}

Effect of increasing the lipid ratio can be seen from Table 4 which shows that with lipid having lower
Carbon-Chain length of fatty acids, there is a perceptible decrease in release rate at every time point $(1 \mathrm{hr}, 6 \mathrm{hr}$ and $12 \mathrm{hr}$ ), when the lipid part is increased from 1 to 1.25 but for compritol $\left(\mathrm{C}_{22}\right.$-behenic acid lipid) with the highest number of $\mathrm{C}$-atom in the alkyl chain of its fatty acid, the decrease in release is barely perceptible. For Dynasan and Precirol increase in lipid ratio from 1 to 1.25 provides better matrix cover to decrease drug release rate. ${ }^{36}$

When the lipid ratio is changed from 1.25 to 1.50 insignificant decreases in release rate is observed for all the three lipids at all three observed time points. ${ }^{37}$

When the $12^{\text {th }}$ hr. dissolution data of each lipid was statistically analyzed across its different ratios used i:e 1:1, 1:1.25 and 1:1.5, the results revealed significant difference between the release of Dynasan 1:1, 1:1.25 and 1:1.5 and also for different ratios of Precirol (calculated $p<0.0001$ ) but insignificant difference for release from different ratios of Compritol (calculated $p=0.8149$ ) as shown in Table 5 .

Thus, from the result it can be concluded that the release retardant effect given by the lipid is in the order dynasan $<$ precirol< compritol. Thus, a lipid with greater 

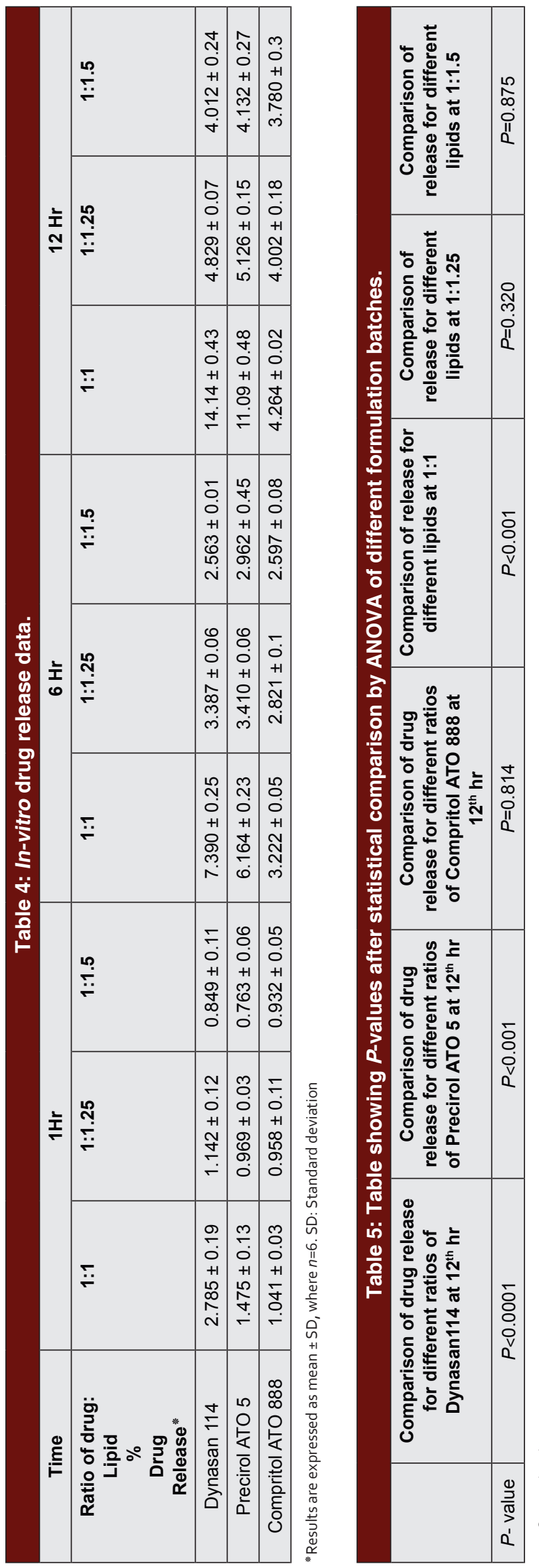

numbe of C-atoms can be used in small amount to give a low release rate for a hydrophilic drug as compared to lipids with less number of $\mathrm{C}$-atoms in the fatty acid. Also, the advantage of increasing the ratio of lipid in the tablet matrix can only be seen upto a certain level above which no benefit is obtained in terms of decrease in the release rate. Thus, batch having $100 \mathrm{mg}$ compritol was selected as it showed good release retardant effect at low level. ${ }^{38}$

The release data of this batch was subjected to kinetic modelling by zero order, first order, Higuchi and Korsmeyer peppas models to determine the mechanism of drug release.

\section{Kinetic modelling of selected batch}

Table 6 shows the $R^{2}$ and release constants for various kinetic models for release data of batch Compritol $100 \mathrm{mg}$ tablet. It can be seen that highest $R^{2}(0.967)$ has been obtained for Higuchi model making it the best fit model for release kinetic and giving evidence for diffusion-controlled release of drug. The value of $n=2.8$, obtained from Korsmeyer peppes model equation elucidates the mechanism of release of drug to be super case -2 transport. ${ }^{39}$

\section{DISCUSSION}

The results of drug-excipient compatibility study conducted by FTIR and DSC showed no interactions between the drug and the lipids used as the FTIR and DSC graphs showed no major changes in the position of peaks obtained. Minor shifts in the peaks are considered acceptable as the presence of excipients acts as an impurity for the drug.

The angle of repose characterizes internal friction or cohesion of the particles. A high value of angle of repose shows the powder to be cohesive and a low value indicates a non-cohesive powder. The values (Table 2) for angle of repose $(<30)$ indicated good flow properties of granules and this was further supported by low Carr's compressibility (12-14.5\%) index and Hausner ratio values (less than 0.89). Particle size distribution, particle shape and the tendency of particle to adhere together determines the bulk density of the powder. The results obtained for bulk and tapped density suggested good packing capacity of the granules prepared.

Very little variation in thickness of tablets of each formulation batch suggests consistency in particle size of the granules giving uniform behavior during compression. The hardness of all the batches of tablets 
Table 6: Kinetic modelling of release data of DC1 batch.

\begin{tabular}{|c|c|c|c|c|c|c|c|c|}
\hline \multirow{2}{*}{$\begin{array}{c}\begin{array}{c}\text { Formulation } \\
\text { Name }\end{array} \\
\text { DC1 } \\
\end{array}$} & \multicolumn{2}{|c|}{ Zero Order } & \multicolumn{2}{|c|}{ First Order } & \multicolumn{2}{|c|}{ Higuchi } & \multicolumn{2}{|c|}{ Korsmeyer Peppes } \\
\hline & $R^{2}$ & $\mathrm{~K}_{0}$ & $R^{2}$ & $\mathrm{~K}_{1}$ & $R^{2}$ & $\mathbf{K}_{\mathrm{H}}$ & $R^{2}$ & $\mathrm{~K}_{\mathrm{p}}$ \\
\hline \multirow{2}{*}{$\begin{array}{l}R^{2} \text { and release } \\
\text { constant }\end{array}$} & \multirow[t]{2}{*}{0.7986} & \multirow[t]{2}{*}{0.4426} & \multirow[t]{2}{*}{0.8194} & \multirow[t]{2}{*}{0.0960} & \multirow[t]{2}{*}{0.9676} & \multirow[t]{2}{*}{1.252} & 0.7404 & 1.0043 \\
\hline & & & & & & & \multicolumn{2}{|c|}{$n=2.8$} \\
\hline
\end{tabular}

was within the desired range. Adequate hardness is desired to maintain integrity of tablet during handling. The release data clearly shows that at lower levels of lipids (at 1:1 level) there is a discernible change in release rate on changing the lipids type at all the time points considered (at $1 \mathrm{hr}, 6 \mathrm{hr}$ and $12 \mathrm{hr}$ ) as is also evident from the results of statistical analysis given above but as the lipid level is increased to 1.25 and 1.5 the difference in release becomes smaller and almost insignificant (calculated $\mathrm{p}$ value greater than 0.05 for both ratios)for different lipid types. The probable reason for this effect could be that at higher lipids levels the drug gets completely surrounded by the lipids and so the individual hydrophobicity of the lipid becomes less important in controlling the release whereas at lower levels the individual hydrophobicity of the lipids play a role in controlling the release. At lower levels (1:1) it can be seen at all three selected time points for the composition, Compritol shows the best potential for retarding the release of the drug (as it gives the least release at $1 \mathrm{hr}, 6 \mathrm{hr}$ and $12 \mathrm{hr}$ ) indicating its higher hydrophobicity as is evident from the number of carbon atom in its fatty acid chains $\left(\mathrm{C}_{22}\right)$ as compared to Dynasan $114\left(\mathrm{C}_{14}\right)$ and Precirol $\left(\mathrm{C}_{16} / \mathrm{C}_{18}\right)$. It has been shown that as the alkyl chain length of fatty acid increase the hydrophobicity of resulting lipid also increases as has also been reported by Li et al. and Sudha et al. ${ }^{40,41}$

Effect of increasing the lipid ratio can be seen from Table 4 which shows that with lipid having lower Carbon-Chain length of fatty acids there is a perceptible decrease in release rate at every time point $(1 \mathrm{hr}, 6 \mathrm{hr}$ and $12 \mathrm{hr}$ ), when the lipid part is increased from 1 to 1.25 but for compritol $\left(\mathrm{C}_{22}\right.$-behenic acid lipid) with the highest number of $\mathrm{C}$-atom in the alkyl chain of its fatty acid, the decrease in release is barely perceptible. The reason behind this trend is probably that compritol because of its higher chain length of fatty acid provides sufficient hydrophobicity at lower levels to minimize water permeation, wetting and dissolving of drug particle and then diffusion and any further increase in the lipid ratio does not provide any significant benefit in terms of decrease in release rate. But for dynasan and precirol increase in lipid ratio from 1-1.25 provides better matrix cover to decrease drug release rate. ${ }^{42,43}$
When the lipid ratio is changed from 1.25 to 1.50 , insignificant decrease in release rate (as compared to 1:1 ratio) is observed for all the three lipids at all three observed time point probably because the matrix gets saturated with lipid at 1.25 level providing maximum coverage to drug particles and minimizing water permeation and drug diffusion and thus giving no further benefit in increasing the lipid ratio to 1.5 as has also been reported by Quadir et al. ${ }^{44}$

Thus, from the result it can be concluded that the release retardant effect given by the lipid is in the order dynasan< precirol< compritol. It can also be interpreted that as the number of $\mathrm{C}$-atoms in the alkyl chain of the fatty acid of lipid increases, its hydrophobicity increases potentiating its release retardant property and minimizing its amount in forming the release retarding matrix. ${ }^{45}$ These results are analogous with result of Abd-Elbary et al. who had formulated lipid matrix tablet of Etodolac using sodium stearate as lipid matrix former.

Thus, a lipid with greater number of $\mathrm{C}$-atoms can be used in small amount to give a low release rate for a hydrophilic drug as compared to lipids with less no of $\mathrm{C}$-atoms in the fatty acid. Also, the advantage of increasing the ratio increased of lipid in the tablet matrix can only be seen upto a certain level above which no benefit is obtained in terms of decreasing the release rate. Thus, batch having $100 \mathrm{mg}$ compritol was selected as it showed good release retardant effect at low level of lipid. ${ }^{46}$

The release data of this batch when subjected to kinetic modelling showed the release to be dominated by Higuchi model $\left(R^{2}=0.9676\right)$ suggesting diffusion controlled release as it is a lipid matrix tablet. The value of $n=2.8$, obtained from Korsmeyer peppas equation elucidates

The mechanism of release of drug to be super case-2 transport which is characterized by relaxation of polymer. ${ }^{47}$

\section{CONCLUSION}

The study was carried out with the objective of comparing the release retardant effect of the three novel lipids (Compritol ATO 888, Precirol ATO and 
Dynasan 114) by preparing sustained release tablets of highly water-soluble drug (Theophylline). The mixture of theophylline and three novel lipids were compressed by direct compression method. Drug and novel lipids interaction was determine by FTIR spectroscopy and DSC. The drug release from the sustained release tablet was studied using USP- II dissolution apparatus and other evaluation parameters were found to be within acceptable range. The release was analysed to determine the lipids showing the best retardant effect. The study showed that Compritol ATO 888 was more hydrophobic, as it has more numbers of Carbon-atoms in its fatty acid chain, as compared to Precirol ATO 5 and Dynasan 114 and demonstrated most effective release retardant effect.

\section{ACKNOWLEDGEMENT}

The authors are thankful to Gattefosse Corp, France and IOI Oleo GmbH Corp, Germany for providing gift sample of Compritol ATO 888, Precirol ATO 5 and Dynasan 114.

\section{CONFLICT OF INTEREST}

The authors declare no conflict of interest.

\section{ABBREVIATIONS}

BCS: Bio pharmaceutics Classification System; FT-IR: Fourier Transform Infra-Red; DSC: Differential scanning calorimetry; USP: United State Pharmacopoeia; mg: Milligram; BD: Bulk Density; TD: Tapped Density; \%: Percentage; ${ }^{\circ} \mathrm{C}$ : Degree Centigrade; UV: Ultra-Violet; rpm: Revolution Per Minute; $\mu \mathrm{g} / \mathrm{mL}$ : Microgram/Millilitre; SD: Standard Deviation;

\section{REFERENCES}

1. Mahaparale PR, Kasture PV, Deshmukh SS, et al. Sustained release matrices of Metoprolol succinate using Compritol 888 ATO and Precirol ATO 05. J Pharm Res. 2006;5(1):10-4

2. Wise DL. In Handbook of Pharmaceutical Controlled Release Technology. CRC Press. 2005;435-40.

3. Ratilal D, Gaikwad PD. An Overview on Sustained Release Drug Delivery System. Int J Res and App Pharma. 2011;1701-8.

4. Tee AK, Koh MS, Gibson PG, Lasserson TJ, Wilson AJ. Long acting beta-2 agonist versus theophylline for maintenance treatment of asthma. Cochr Data Syst Rev. 2007;18(3):1281-6.

5. Barnes PJ. Theophylline: New perspectives for an old drug. Am J Respircrit Care Med. 2003;167(6):813-8.

6. Zhua B, Haghia M, Goudc M, Younga PM, Traini D. The formulation of a pressurized metered dose inhaler containing theophylline for inhalation. Eur J Pharma Sci. 2015;76(1):68-72.

7. Ertan G, Karasulu HY, Karasulu E, Ege MA, Köse T, Güneri T. A new in vitrol in vivo kinetic correlation method for nitro furantoin matrix tablet formulations. Dr Dev Ind Pharm. 2000;26(7):737-43.
8. Patere SN, Desai NS, Jain AK, et al. Compritol ${ }^{\circledR} 888$ ATO a lipid excipient for sustained release of highly water soluble active, formulation, scale-up and IVIVC study. Current Drug Del. 2013;10(5):548-56.

9. Korsmeyer RW, Gurny R, Doelker E, Buri P, Peppas NA. Mechanisms of solute release from porous hydrophilic polymers. Int J Pharm. 1983;15(1):25-35.

10. https://www.rose-hulman/edu/brandt/Chem330/Lipid properties.

11. Jannin V, Musakhanian J, Marchaud D. Approaches for the development of solid and semi-solid lipid-based formulations. Adv Drug Deliv Rev. 2008;60(6):734-6.

12. Shady M, Amin A, Gawad N. Comparative study on the different techniques for the preparation of sustained-release hydrophobic matrices of a highly water-soluble drug. Drug Disc Thera. 2010;4(6):484-92.

13. Rosiaux $Y$, Jannin $V$, et al. Solid lipid excipients-Matrix agents for sustained drug delivery. Journal of Controlled Release. 2014;18:18-30.

14. Kumar SP, Rani N, Rana V. Investigation of different lipid based materials as matrices designed to control the release of a hydrophobic drug. Int J Pharm Sci Drug Res. 2009;1(3):158-63.

15. Khatik T, Moravkar K. Development of sustained release Aceclofenac lipid matrix tablet using continuous melt granulation technique. Am J Pharm Tech Res. 2018;8(3):234-48.

16. Singh D, Sharma V. Development of lipid micromatrices based sustained release tablets of Glipizide: Suitability of stearic acid as release retardant. Pharm Biomed Res. 2016;2(2):9-30.

17. Jannin V, Leccia E, Rosiaux Y, Doucet J. Evolution of the Microstructure of Sustained-release Matrix Tablets during Dissolution and Storage. Indian J Pharm Sci. 2018;80(6):1011-20.

18. Roberts $M$, Velluccil D. Development and evaluation of sustained-release Comprito $^{\circledR} 888$ ATO matrix mini-tablets. Drug Development and Industrial Pharmacy. 2012;38(9):1068-76.

19. Meeus L. Direct Compression Versus Granulation. In Pharmaceutical Technology Europe. 2011;23(3).

20. Bushra R, Shoaib MH, Aslam N, Hashmat D, Rehman MU. Formulation development and optimization of ibuprofen tablets by direct compression method. Pak J Pharm Sci. 2008;21(2):113-20.

21. Clark. Clark's Analysis of Drugs and Poisons. $2^{\text {nd }}$ ed. Pharmaceutical Press. Ame Pharma Asso. 2004.

22. Harland R, Dubernet C, Benoit JP, Peppas N. A model of dissolutioncontrolled, release from non-swellable polymeric microspheres. J Control Rel. 2003;6(1):282-91.

23. Mi JK, Hyeong SL, Yook HN, et al. Pharmacokinetic interaction between eperisone hydrochloride and Aceclofenac: A randomized, open label, crossover study of healthy Korean men. Clin Thera. 2013;35(10):1528-35.

24. Viveksarathi K, Rajarajan R, Kannan K, Manavalan R. Dosage form design and evaluation of eperisone hydrochloride matrix film coated extended release tablets. Int J Pharm Pharma Sci. 2012;4(2):575-81.

25. Patel NM, Soniwala MM. Influence of release enhancer on release of Venlafaxine $\mathrm{HCL}$ from Glyceryl Behenate matrix tablet. Indian Drugs. 2008;45(2):98-104.

26. Reddy KR, Mutalik S, Reddy S. Once-daily sustained release matrix tablets of nicorandil: Formulation and in vitro evaluation. AAPS Pharm Sci Tech. 2003;4(4):1-9.

27. Tiwari SB, Murthy TK, Pai MR, Mehta PR, Chowdhary PB. Controlled Release formulation of Tramadol Hydrochloride using Hydrophilic and Hydrophobic Matrix system. AAPS Pharm Sci Tech. 2003;4:110-6.

28. Sayeed F, Garg G. Modulated Release of Theophylline from Controlled Release Matrix Tablets. Int J Pharm Res Scho. 2014;3(1):817-24.

29. Opota DO, Kaloustian J, Sengal PK, Vemba1 AT, Cimangal AK. The Efficiency of Glyceryl Behenate as Sustained-Release Agent Compared with Hydroxypropyl cellulose In Tablets. Int J Pharm Tech Res. 2013;5(2):623-8.

30. Madgulkar AR, Bhalekar M, Shiradkar MR. Compritol and precirol: Innovative pharmaceutical excipients. Asian J Chem. 2007;19(1):454-8.

31. Hamdani J, Moës AJ, Amighi K. Physical and thermal characterisation of Precirol $^{\circledR}$ and Compritol $^{\circledR}$ as lipophilic glycerides used for the preparation of controlled-release matrix pellets. Int J Pharma. 2003;260(1):47-57.

32. Severino PC, Pinho SC, Souto EB, Santana MHA. Crystallinity of Dynasan 114 and Dynasan 118 matrices for the production of stable Miglyol loaded nanoparticles. J Ther Analy and Calori. 2012;1-8. 
33. Aburahma MH, Badr-Eldin SM. Compritol 888 ATO: A multifunctional lipid excipient in drug delivery systems and Nanopharmaceuticals. Exp Opin Drug Deliv. 2014;11(11):1-19.

34. Patel MP, Patel MR, Middha A. Formulation of sustain release matrix tablet of tramadol hydrochloride using hydrophobic polymers. Int J Pharma Res and Dev. 2013;5(1):56-64.

35. Abd-Elbary A, Tadros Ml. Sucrose Stearate-Enriched Lipid Matrix Tablets of Etodolac: Modulation of Drug Release, Diffusional Modeling and Structure Elucidation Studies. AAPS Pharm Sci Tech. 2013;14(2):656-68.

36. Deore RK, Kavitha K, Tamizhmani TG. Preparation and valuation of sustained release matrix tablets of tramadol hydrochloride using glyceryl palmitostearate. Trop J Pharma Research. 2010;9(3):275-81.

37. El-Sayed GM, El-Said Y, Meshali MM, Schwartz JB. Kinetics of theophylline release from different tablet matrices. S T P Pharma Pratiques. 1996;6(6):390-7.

38. Kreye F, Siepmann F, Siepmann J. Drug release mechanisms of compressed lipid implants. Int J Pharm. 2011;404(1-2):27-35.

39. Costa P, Lobo SJM. Modeling and comparison of dissolution profiles. Eur J Pharma Sci. 2001;13(2):123-33.

40. Li FQ, Hu JH, Deng JX, Su H, Xu S, Liu JY. In vitro controlled release of sodium ferulate from Compritol 888 ATO based matrix tablets. Int J Pharm. 2006;324(2):152-7.

\section{PICTORIAL ABSTRACT}

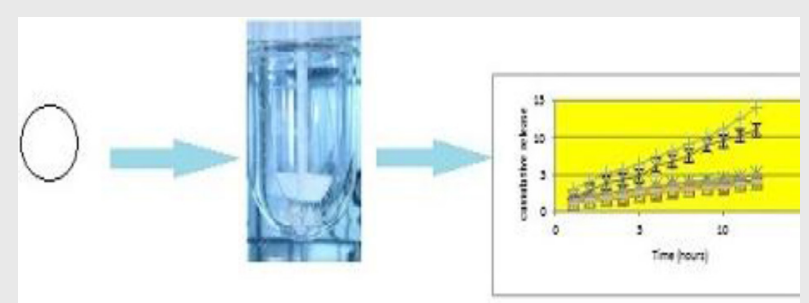

Pictorial representation of release retardant effect of lipids on formulated tablets

\section{About Authors}

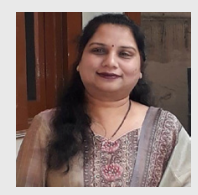

Shweta Agarwal is an Associate Professor, Deapartment of Pharmaceutics, L.R Institute of Pharmacy, Solan. She has 15 years of teaching and research experience and has published more than 30 review and research articles in peer reviewed journals. she has reviewed papers for several reputedlnternational journals and has mentored 20 post-graduate students. Her areas of interest include mucoadhesive systems, colidal drug delivery and topical gels.
41. Sudha BS, Sridhar BK, Srinatha A. Modulation of tramadol release from a hydrophobic matrix: Implications of formulations and processing variables. AAPS Pharm Sci Tech. 2010;11(1):433-40.

42. Bhagwat DA, Kawtikwar PS, Sakarkar DM. Formulation and the in-vitro and biopharmaceutical evaluation of sustained release tablet of verapamil $\mathrm{HCL}$ using precirol ATO 5 through melt granulation technique. Asia J Pharma. 2009;3(4):278-4.

43. Dhameliya PB, Vyas JR, Narola M. Preparation and evaluation of sustained release tablet of eperisone hydrochloride by compritol ato 888 as a matrix forming agent. J Dr Deli and Thera. 2014;4(3):132-7.

44. Quadir MA, Rahman MS, Karim MZ, Akter S, Awkat MT. Evaluation of hydrophobic materials as matrices for controlled-release drug delivery. Pak J Pharm Sci. 2003;16(2):17-28.

45. Kallakunta VR, Tiwari R, Sarabu S, Bandari S, Repka MA. Effect of formulation and process variables on lipid based sustained release tablets via continuous twin screw granulation: A comparative study. Eur J Pharma Sci. 2018;1-45.

46. Rosiaux $Y$, Jannin V, Hughes S, Marchaud D. Solid lipid excipients matrix agents for sustained drug delivery. J Contr Rel. 2014;188:18-30.

47. Reza MS, Quadir MA, Haider SS. Comparative evaluation of plastic, hydrophobic and hydrophilic polymers as matrices for controlled release drug delivery. J Pharm Pharma Sci. 2003;6(2):282-91.

\section{SUMMARY}

In the present study the release retardant effect of 3 novel lipids, Compritol ATO 888, Precirol ATO5 and Dynasan 114 was compared by using BCS class I drug, Theophylline, as the model drug. Drugexcipient compatibility was checked by FTIR and DSC, showing the drug to be compatible with the lipids used. Sustained release tablets of theophylline were formulated taking the 3 lipids in different ratios (1:1, 1:1.25 and 1:1.5) with respect to the drug. All the 9 prepared batches of tablets were subjected to in-vitro drug release study, using USP type-II apparatus. From the drug release data obtained, DC1 batch having $100 \mathrm{mg}$ drug and $100 \mathrm{mg}$ Compritol showed optimum, desirable release rate and was selected for further studies. Release data of DC1 batch was used for kinetic modeling. The release showed to be following Higuchi model $\left(R^{2}=0.967\right)$ and release mechanism was found to be super case 2 transport $(n=2.8)$ from Korsmeyer-Peppas model. The results of the study showed the release retardant potential of the lipids to be in the order Dynasan $<$ Precirol< Compritol, establishing Compritol as the best release retardant lipids from the 3 lipids used. Compritol possessed superior potential for retarding the release of drug probably because of greater number of Carbon atoms (C22) in its fatty acid chain, making it more hydrophobic than other lipids studied.

Cite this article: Agarwal S, Devi R, Sharma RB, Sharma A. Comparison of Release Retardant Effect of Some Novel Lipids by Formulating Sustained Release Tablet of BCS Class 1 Drug. Indian J of Pharmaceutical Education and Research. 2020;54(2s):s241-s250. 